\title{
Polyphyllin VI Induces Apoptosis and Autophagy via Reactive Oxygen Species Mediated JNK and P38 Activation in Glioma
}

This article was published in the following Dove Press journal: OncoTargets and Therapy

\author{
Wei Liu' \\ Yi Chai ${ }^{1}$ \\ Libo Hu' \\ Junhua Wang ${ }^{2}$ \\ Xin $\operatorname{Pan}^{2}$ \\ Hongyu Yuan ${ }^{3}$ \\ Zitong Zhao $\mathbb{1 D}^{3}$ \\ Yongmei Song $\mathbb{D}^{3}$ \\ Yuqi Zhang'

\begin{abstract}
'School of Clinical Medicine, Tsinghua University, Beijing 10084, People's Republic of China; ${ }^{2}$ Department of Neurosurgery, Yuquan Hospital, School of Clinical Medicine, Tsinghua University, Beijing 100040, People's Republic of China; ${ }^{3}$ State Key Laboratory of Molecular Oncology, National Cancer Center, Cancer Hospital, Chinese Academy of Medical Sciences and Peking Union Medical College, Beijing I0002I, People's Republic of China
\end{abstract}

Background: Polyphyllin VI (PPVI), a bioactive component derived from a traditional Chinese herb Paris polyphylla, exhibits potential antitumor activity against hepatocellular carcinoma, as well as breast and lung cancers. However, its effect on glioma remains unknown.

Methods: Five glioma cell lines (U251, U343, LN229, U87 and HEB) and an animal model were employed in the study. Anti-proliferation effects of PPVI were first determined using CCK- 8 cell proliferation and clone formation assays, then reactive oxygen species (ROS), cell cycle progression and apoptosis effects measured by flow cytometry. The effect of PPVI on protein expression was quantified by Western blot analysis.

Results: Data showed that PPVI inhibited the proliferation of glioma cell lines by modulating the G2/M phase. Additionally, incubation of cells with PPVI promoted apoptosis, autophagy, increased accumulation of ROS and activated ROS-modulated JNK and p38 pathways. On the other hand, N-acetyl cysteine, a ROS inhibitor, attenuated PPVItriggered effects. Furthermore, JNK and p38 inhibitors ameliorated PPVI-triggered autophagy and apoptosis in glioma cells. In vivo assays showed that PPVI inhibited tumor growth of U87 cell line in nude mice.

Conclusion: Overall, these data suggested that PPVI might be an effective therapeutic agent for glioma.

Keywords: polyphyllin VI, glioma, autophagy, apoptosis, reactive oxygen species

\section{Introduction}

Glioma is the most predominant type of intracranial tumor with high mortality and low survival rates. ${ }^{1,2}$ Although various treatment options, including neurosurgical re-section and adjuvant chemoradiotherapy, prolong the lives of patients with this condition, life expectancy remains low due to tumor recurrence. ${ }^{1,3}$ The dismal treatment outcomes against glioma can further be attributed to its heterogeneity, aggressive growth and resistance to chemoradiotherapy. ${ }^{4}$ To improve prognosis, research efforts have focused on the identification of novel anti-cancer agents, albeit with little success. ${ }^{5}$ It is, therefore, imperative to prospect for more effective chemotherapeutic agents against glioma.

Polyphyllin VI (PPVI) (Figure 1A, a steroidal saponin isolated from Paris polyphylla), has been shown to have anti-cancer against various types of malignancies. For example, Teng et $\mathrm{al}^{6}$ demonstrated that PPVI could suppress the proliferation of non-small-cell lung cancer, while in hepatocellular carcinoma, it
Correspondence: Yuqi Zhang

Medicine, Tsinghua

of China

Email doctorzyq@।26.com

Yongmei Song

State Key Laboratory of Molecular

Oncology,National Cancer Center,

Cancer Hospital, Chinese Academy of

Medical Sciences and Peking Union

Medical College, 17 Panjiayuannanli,

Chaoyang, Beijing I0002I, People's

Republic of China

Email symlh2006@I63.com 
A

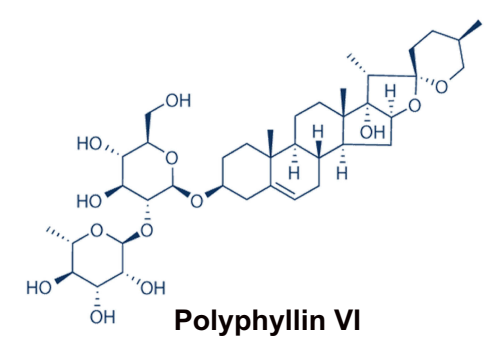

C

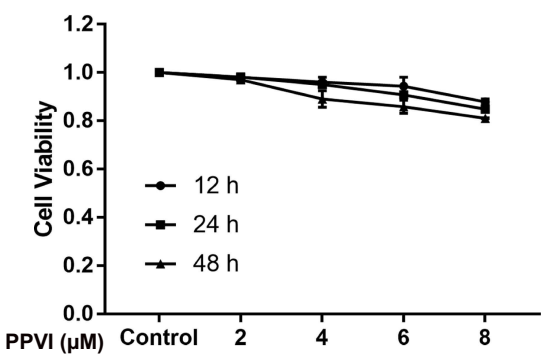

B

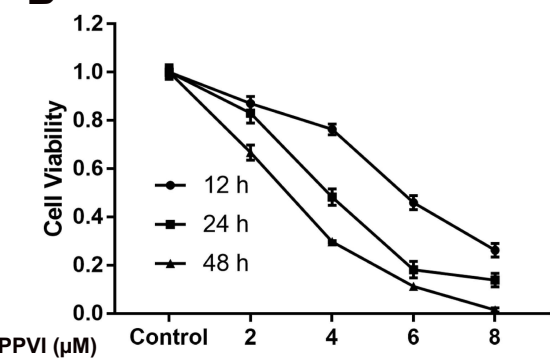

U87

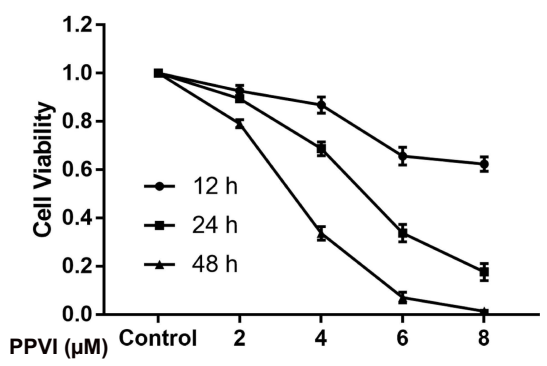

U251

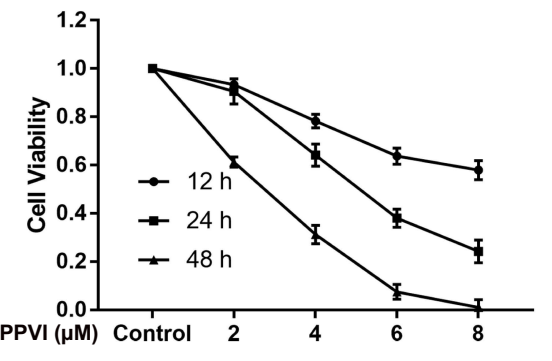

U343

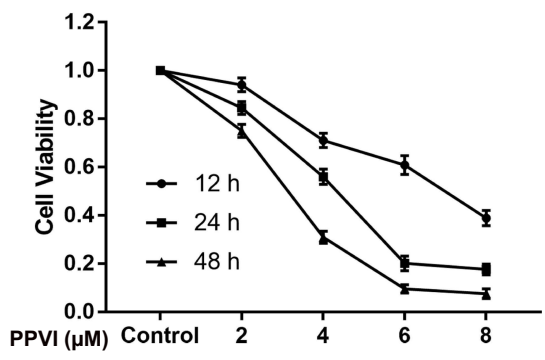

D

U87

E

U251
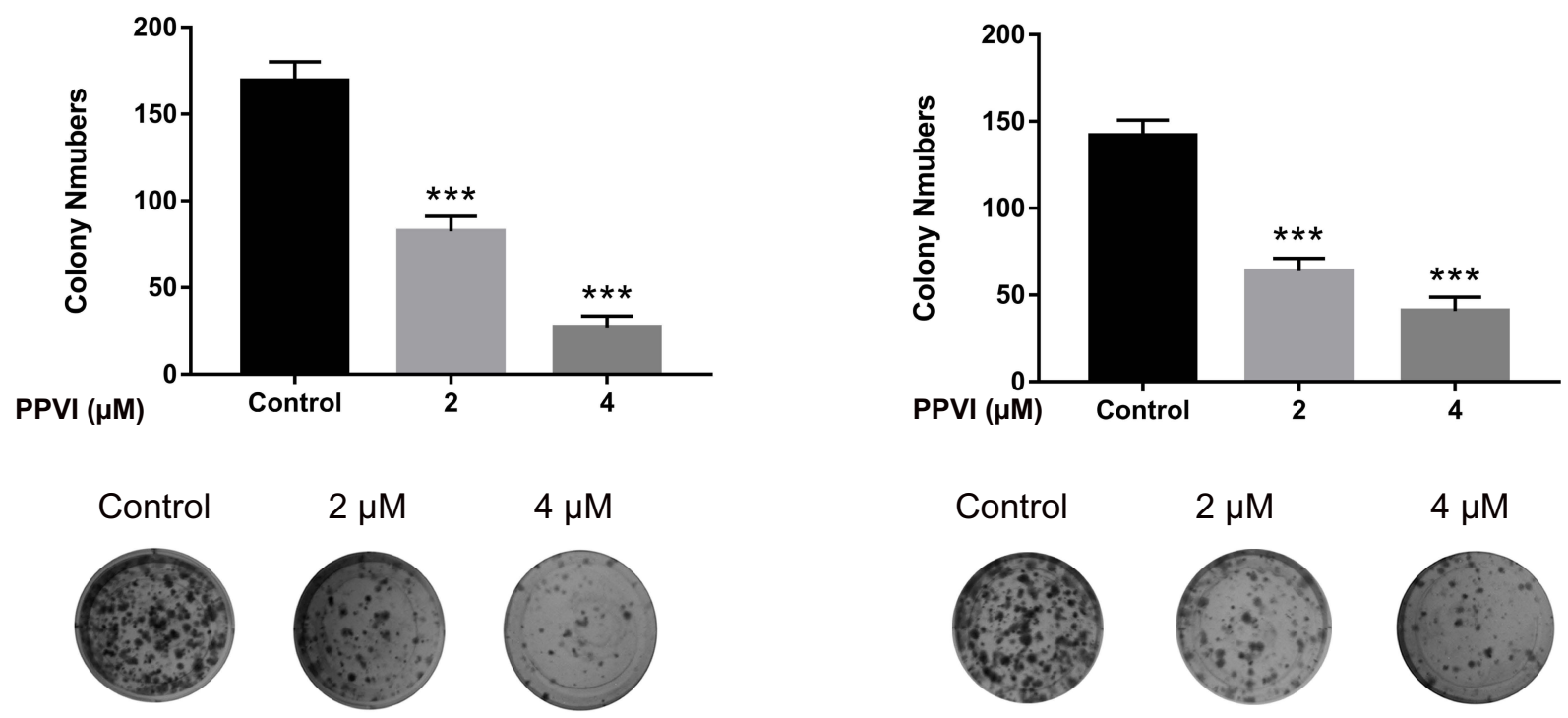

$4 \mu \mathrm{M}$

Figure I The anti-proliferative effect of PPVI in glioma cell line. (A) The structure of PPVI. U87, U25I, LN229, U343 (B) and HEB (C) were treated with PPVI (0,2,4,6 and 8 $\mu \mathrm{M})$ for 12.24 and $48 \mathrm{hrs}$. Cell viability was detected by CCK-8 assay. (D, E) The results of colony formation assays of U87 and U25 I cells incubated with PPVI (0,2,4 $\mu$ M). $* * * p_{p}<0.001$.

was found to induce apoptosis via the Fas death pathway. ${ }^{7}$ However, the effect of PPVI on glioma remains unknown.

Tumor cells are usually accompanied by abnormal changes in the cell cycle. However, several cytotoxic agents have been identified and these inhibit proliferation of such cells by arresting their cell cycle. ${ }^{8}$ The regulatory pathways of the cell cycle focus on precise regulation of various cycle-dependent protein kinase activities, whose regulatory functions are controlled by their protein levels. Among the cyclins, cyclin B1 represents the first cell cycle protein. This protein is predominantly expressed in the $\mathrm{G} 2$ / M phase and ensures proper initiation of mitosis. ${ }^{9}$

Apoptosis and autophagy are two forms of programmed cell death. ${ }^{10,11}$ Apoptosis is one of the most 
important anti-tumor mechanisms, and represents an important target during the designing of anti-tumor agents. $^{12}$ On the other hand, autophagy maintains homeostasis through a lysosome-dependent mechanism and controls genome stability. ${ }^{13}$ Accumulating evidence shows that chemotherapeutics can simultaneously modulate both apoptosis and autophagy. ${ }^{14,15}$ However, the relationship between the two types of programmed cell death remains unclear.

Reactive oxygen species (ROS) are produced in mitochondria, where are also the main targets of ROS. ${ }^{16}$ ROS not only participate in apoptosis and autophagy but also activates multiple signaling pathways, including c-Jun N-terminal kinase (JNK), p38 and extracellular regulated protein kinases (ERK). In addition, ROS have been shown to promote cell proliferation and differentiation. ${ }^{17,18}$

In the present study, we evaluated potential anticancer activity of PPVI in glioma cells and found that it blocks cell cycle progression and triggers apoptosis as well as autophagy in these cells. Functionally, the results revealed that the process might be dependent on ROS-modulated JNK and p38 pathways. Taken together, these findings indicated that PPVI could be a potential therapy for glioma.

\section{Methods}

\section{Reagents}

PPVI (purity $>98 \%$ ) was supplied by Herbpurify Co. Ltd, Chengdu, China. The preparation of a detailed process is described previously. ${ }^{19}$ Z-VAD-FMK (z-VAD, C1202), N-acetyl-L-cysteine (NAC, s0007), SP600125 (SP, S1876) and SB203580 (SB, S1863) were supplied by BeyoTime Biotech (Nanjing, China). 3-methyladenine (3-MA, s2767) were purchased from Selleckchem (Houston, TX, USA).

\section{Cell Lines and Culture Conditions}

Cell lines U87, LN229, U251, and U343 were obtained from ATCC (American Type Culture Collection). Human normal brain glial cells (HEB) were acquired from the Cell Culture Center (Dongge Biotech, Beijing, China). Culturing of all cell lines was done on DMEM medium supplemented with 10\% FBS (HyClone, USA) and maintained in an incubator at $37^{\circ} \mathrm{C}$, and $5 \% \mathrm{CO}_{2}$.

\section{Cell Viability Assay}

Approximately 2000 glioma cells were re-suspended in $100 \mu \mathrm{L}$ of complete medium and cultured in 6-well plates for $24 \mathrm{hrs}$. Cells were pretreated with $10 \mathrm{mM} \mathrm{NAC}, 20 \mu \mathrm{M}$
SP, $20 \mu \mathrm{M}$ SB, $20 \mu \mathrm{M} \mathrm{z-VAD}$ and $3 \mathrm{mM} 3-\mathrm{MA}$ for $1 \mathrm{hr}$ where indicated. The cells were treated with varying concentrations of PPVI $(0,2,4,6$, and $8 \mu \mathrm{m})$ followed by a 12, 24 and $48 \mathrm{hrs}$ incubation. Thereafter, the cells were treated with the WST-8 reagent from CCK-8 (NCM Biotech, Suzhou, China) for 2 hrs, then their viability assayed by detecting the absorbance at OD $450 \mathrm{~nm}$.

\section{Clone Formation Assay}

After incubation with $0,2,4 \mu \mathrm{m}$ of PPVI, about 1000 glioma cells were re-suspended in $1 \mathrm{~mL}$ complete medium then seeded in a 6-well plate. After 10 days of culture, cell colonies were fixed, stained, dried followed by determination of colony numbers.

\section{Apoptosis Assays}

To analyze cell death, cells were first pre-treated with 10 mM NAC, $20 \mu \mathrm{M}$ SP, $20 \mu \mathrm{M} \mathrm{SB}, 20 \mu \mathrm{M}$ z-VAD and 3 $\mathrm{mM} 3-\mathrm{MA}$ for $1 \mathrm{hr}$. They were then incubated with $0.2,4$, and $6 \mu \mathrm{m}$ of PPVI for $24 \mathrm{~h}$, approximately $5 \times 10^{4}$ cells collected and apoptosis analyzed using the Annexin V-FITC Kit (Neobioscience, Shenzhen, China) and a flow cytometer (BD Bioscience, USA).

\section{Cell Cycle Analysis}

Approximately $2 \times 10^{5}$ glioma cells were re-suspended in $2 \mathrm{~mL}$ of complete medium and cultured in a 6-well plate for $24 \mathrm{hrs}$. They were then treated with $0,2,4$, and $6 \mu \mathrm{m}$ PPVI and pre-treated for $1 \mathrm{hr}$ with $10 \mathrm{mM}$ NAC, $20 \mu \mathrm{M}$ SP, $20 \mu \mathrm{M} \mathrm{SB}, 20 \mu \mathrm{M}$ z-VAD and $3 \mathrm{mM}$ 3-MA. After incubation, the cells were collected and fixed overnight, resuspended in approximately $300 \mu \mathrm{L} \mathrm{PI/RNase} \mathrm{staining}$ buffer and incubated for 15-20 mins in the dark. Finally, the cell cycle distribution of the processed samples was detected by flow cytometry (BD Biosciences, USA).

\section{Transwell Assays}

A transwell assay (Corning, USA) was carried out to determine the role of PPVI on the invasive ability of glioma cells. Briefly, $3 \times 10^{4}$ cells, after incubation with or without PPVI, were resuspended and passed on the top chamber with the serum-free medium while the bottom chamber of the system was supplemented with complete medium. Migrated cells were fixed and stained after $24 \mathrm{hrs}$ and their images obtained under a microscope. The area occupied by these cells was further measured using Image J software. 


\section{Western Blot Analysis}

Proteins were extracted from cells or tissue using the RIPA buffer (Applygen, China). About $30 \mu \mathrm{g}$ of the protein per lane was detected according to a standard protocol of sodium dodecyl sulfate (SDS)-polyacrylamide gel electrophoresis. Membranes were incubated overnight, at $4^{\circ} \mathrm{C}$, with the following primary antibodies: cleaved-caspase-3 (9661S), E-cadherin (3195S), N-cadherin (4061S), cyclin B1 (4138S), p38 (8690S), cleaved-caspase-8 (8592S), Bax (2774S), Bcl-2 (3498S), Beclin-1 (3495S), JNK (9255S) and cleaved-caspase-9 (9505S) (Cell Signaling Technology, USA); p-JNK (sc-6254) and p-p38 (sc-7973) (Santa Cruz Biotechnology, USA); LC3 (L8918) and $\beta$-actin (A8418) (Sigma, USA). Samples were then incubated with secondary antibodies at $25^{\circ} \mathrm{C}$ for $1 \mathrm{~h}$, and protein bands detected using a Luminescent Image Analyzer LAS-4000 (Fujifilm).

\section{Measurement of ROS Production}

To detect the production of ROS, we employed an ROS Assay Kit (Beyotime Biotech, Nanjing, China) according to the manufacturer's instructions. Results were then analyzed by fluorescent microscopy and a flow cytometer (BD Biosciences, USA).

\section{In vivo Assays}

To investigate the effect of PPVI in vivo, we used 4-week old male BALB/c-nu mice supplied by HFK Bioscience (Beijing, China). The experiments involving mice were approved by the Cancer Hospital, Chinese Academy of Medical Sciences, Experimental Animal Ethics Committee. All mice were housed under pathogen-free environment and all animal care and experiments were performed in accordance with the Institutional Animal Welfare Guidelines issued by Chinese Academy of Medical Sciences. Approximately $1 \times 10^{6}$ of U87 cells were resuspended with $100 \mu \mathrm{L}$ PBS and subcutaneously injected into the left groin of each mouse. Seven days after injection, we randomly placed 10 mice into the PPVI and control groups, with each group containing 5 mice. The PPVI group received an intraperitoneal injection of $100 \mu \mathrm{L}$ of PBS combined with $5 \mathrm{mg} /$ kg PPVI every 2 days, while the control group received 100 $\mu \mathrm{L}$ PBS with $5 \%$ DMSO. After the sixth injection, the tumors were excised and analyzed.

\section{Histopathology and}

\section{Immunohistochemistry}

We collected tissues from sacrificed mice, fixed them with $4 \%$ paraformaldehyde. Histological examination and morphological analysis of tumors were performed by HE staining using Ki-67 (ZSGB-BIO, Beijing, China).

\section{Statistical Analyses}

Data obtained from at least three independent experiments were expressed as mean \pm standard deviations of the mean. We employed one-way analysis of variance (ANOVA) to compare differences among multiple groups, and unpaired Student's $t$-test for comparisons between two groups. The normality of the data was checked by Shapiro-Wilk normality test. The best-fit non-linear sigmoidal doseresponse curves were generated for $\mathrm{IC}_{50}$ determination. All data analyses were performed using GraphPad Prism 7 (GraphPad Software, San Diego, CA, USA).

\section{Results \\ PPVI Suppresses Cell Proliferation in Glioma}

To detect the effect of PPVI on the proliferation of glioma cells, we incubated four cell lines (U251, U343, LN229 and U87) with varying concentrations of PPVI over time (Figure 1B). The results showed that PPVI inhibited the proliferation of all four glioma cell lines. $\mathrm{IC}_{50}$ values of PPVI after $24 \mathrm{hrs}$ were $3.65 \pm 0.428 \mu \mathrm{M}$ in LN229 cells, $5.00 \pm 0.372 \mu \mathrm{M}$ in U87 cells, $5.13 \pm 0.528 \mu \mathrm{M}$ in $\mathrm{U} 251$ cells and $3.99 \pm 0.397 \mu \mathrm{M}$ in U343 cells. Results from the CCK-8 assay, used to examine the toxicity of PPVI on normal HEB cells, indicated limited cytotoxicity after treatment with the drug (Figure 1C).

Next, we performed a colony formation assay to evaluate the long-term effects of PPVI on glioma cell proliferation. We found a marked decrease in the number of colonies following PPVI treatment relative to the control group. Particularly, U87 recorded $169.0 \pm 9.1$ vs $83.2 \pm 7.1$ vs $29.7 \pm 2.9(\mathrm{p}=0.0004)$ (Figure $1 \mathrm{D})$, while $\mathrm{U} 251 \mathrm{had}$ $141.7 \pm 7.4$ vs $63.7 \pm 6.0$ vs $46.7 \pm 4.8(\mathrm{p}=0.0003)$ (Figure 1E). Taken together, these results suggested that PPVI hindered the proliferation of glioma cells, with limited toxic effects on normal cells.

\section{PPVI Inhibits Migration of Glioma Cells}

We used a Transwell assay to assess whether PPVI could affect cell migration. The results demonstrated that migration capacity was abrogated after PPVI treatment in U87 (76.7 $\pm 6.2 \%$ vs $50.0 \pm 4.1 \%$ vs $35.3 \pm 2.4 \%$ vs 14.7 $\pm 3.7 \%, \mathrm{p}=0.0113, \mathrm{p}=0.0009$ and $\mathrm{p}=0.003)$ and $\mathrm{U} 251(61.0 \pm 5.4 \%$ vs $42 \pm 4.3 \%$ vs $27.3 \pm 1.2 \%$ vs 13.3 
$\pm 1.7 \%, \mathrm{p}=0.0174, \mathrm{p}=0.0009$ and $\mathrm{p}=0.0002)($ Figure $2 \mathrm{~A}$ and B). A Western blot analysis, performed to examine the expression of EMT-related proteins showed a significant upregulation of E-cadherin, as well as downregulation of $\mathrm{N}$-cadherin in the PPVI treatment group (Figure 2C). These results indicate that PPVI successfully inhibited the migration of glioma cells.

\section{PPVI Induces Cell Cycle Arrest in Glioma Cells}

To elucidate the mechanisms underlying the antiproliferation effect of PPVI, we analyzed the influence of PPVI on cell cycle by treating the cells with 2.4 and $6 \mu \mathrm{M}$ PPVI for 24 hrs followed by flow cytometry. Compared with the control group, we detected an immense accumulation in the proportion of $\mathrm{G} 2 / \mathrm{M}$ phase after PPVI treatment for 24 $\mathrm{h}$ in U87 $(9.4 \pm 0.80 \%$ vs $18.1 \pm 1.87 \%$ vs $28.8 \pm 2.04 \%$ vs $36.0 \pm 2.45 \%, \mathrm{p}=0.0008, \mathrm{p}<0.0001$ and $\mathrm{p}<0.0001)$ and $\mathrm{U} 251(10.3 \pm 0.86 \%$ vs $15.5 \pm 1.69 \%$ vs $27.8 \pm 1.96 \%$ vs $32.2 \pm 2.07 \%, \mathrm{p}=0.0090, \mathrm{p}=0.0003$ and $\mathrm{p}=0.0001)$ (Figure 3A). Evaluation of levels of cell cycle-related proteins showed that PPVI could limit the expression of cyclin B1in a dose-dependent manner (Figure 3B). These findings indicated that PPVI arrested the progression of the cell cycle thereby hindering the proliferation of glioma cells.

\section{PPVI Induces Apoptosis in Glioma Cells}

We further explored whether PPVI induces apoptosis by examining cell death in U87 and U251 cells using flow cytometry. Compared with control group, the percentage of apoptotic cells increased in the PPVI-treatment groups for U87 (3.1 $\pm 0.82 \%$ vs $15.3 \pm 3.27 \%$ vs $26.7 \pm 3.40 \%$ vs $55.0 \pm 5.35 \%, \mathrm{p}=0.0141, \mathrm{p}=0.0008$ and $\mathrm{p}=0.0002)$ and $\mathrm{U} 251(4.5 \pm 0.41 \%$ vs $12.3 \pm 2.62 \%$ vs $30.3 \pm 3.30 \%$ vs $49.7 \pm 4.50 \%, p=0.0140, p=0.0004$ and $p=0.0001)$ (Figure 4A). Furthermore, PPVI significantly increased expression levels of Bax and cleaved-caspase-3, 8, and 9, but decreased levels of Bcl-2 (Figure 4B).

When a pan-caspase inhibitor, z-VAD, was used to block PPVI-induced apoptosis in glioma cells, it was observed that $4 \mu \mathrm{M}$ PPVI could successfully decrease cell viability by $60.3 \pm 4.21 \%(\mathrm{p}<0.0001)$ in U87 and $59.6 \pm 3.01 \%(\mathrm{p}<$
A
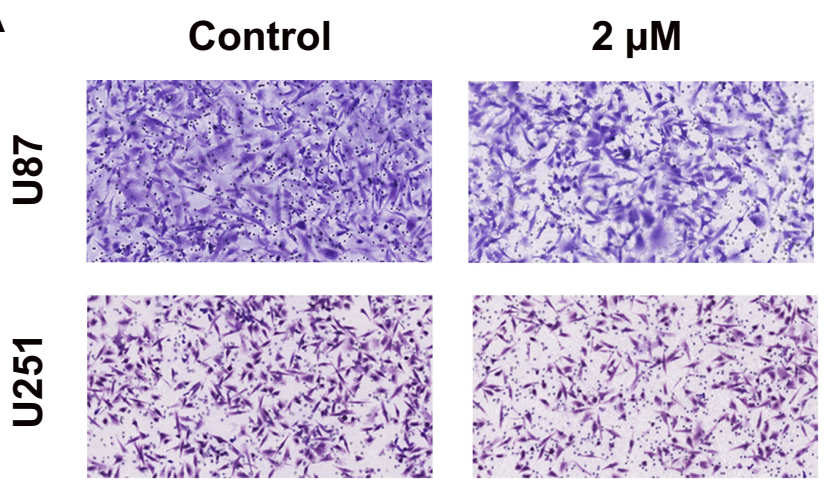

$4 \mu \mathrm{M}$
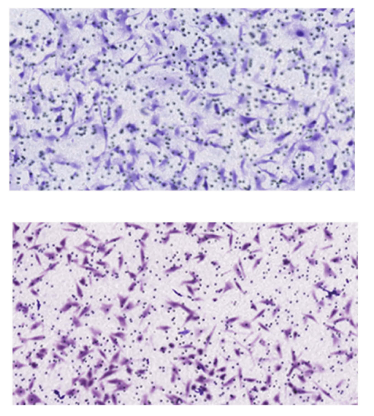

$6 \mu \mathrm{M}$
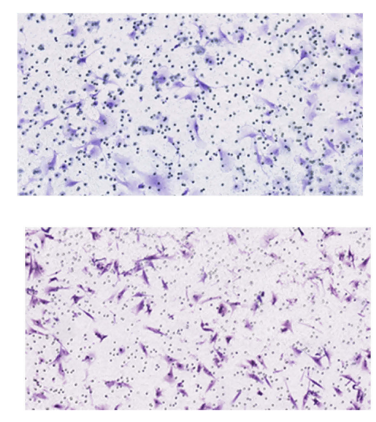

B

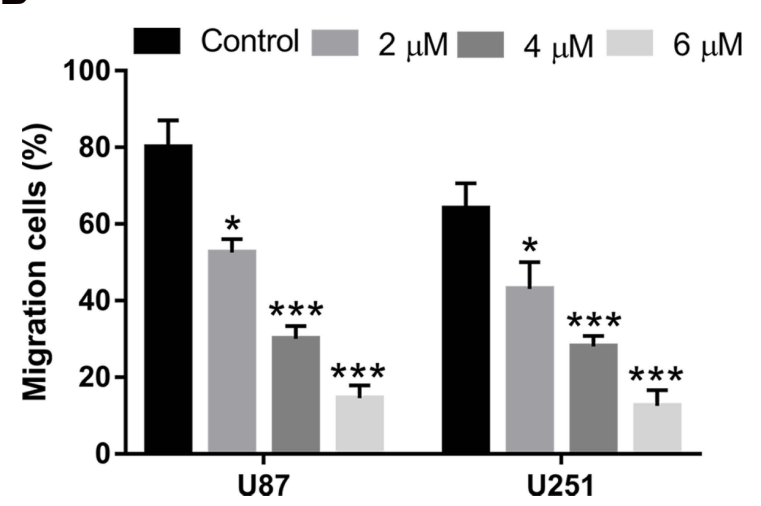

C

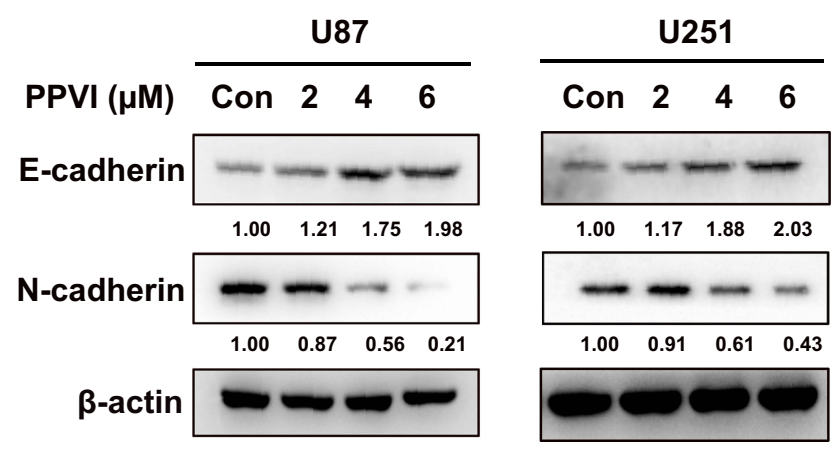

Figure 2 PPVI inhibited cell migration capacity in glioma cells. (A, B) U87 and U25I cells were incubated with PPVI $(0,2,4,6 \mu M)$ and the migration capacity was evaluated by Transwell migration assays. (C) E-cadherin and N-cadherin were evaluated by Western blot. $* \mathrm{p}<0.05, * * * \quad \mathrm{p}<0.001$.

Abbreviations: Con, Control. 
A
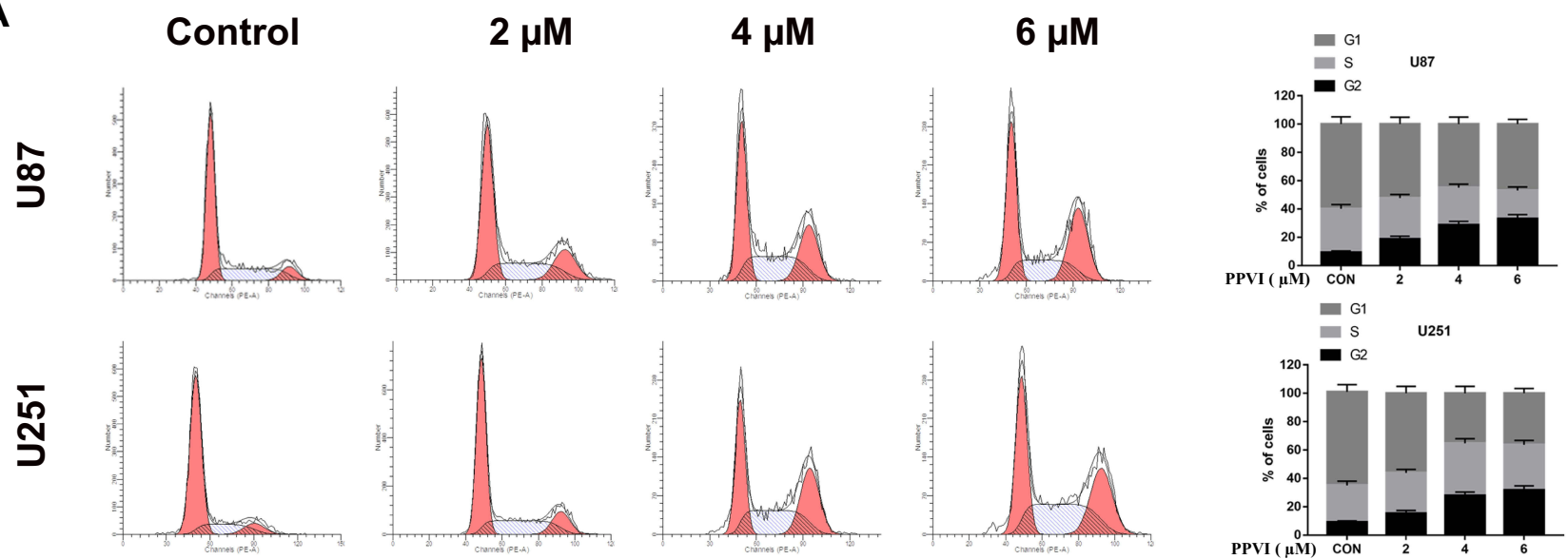

B
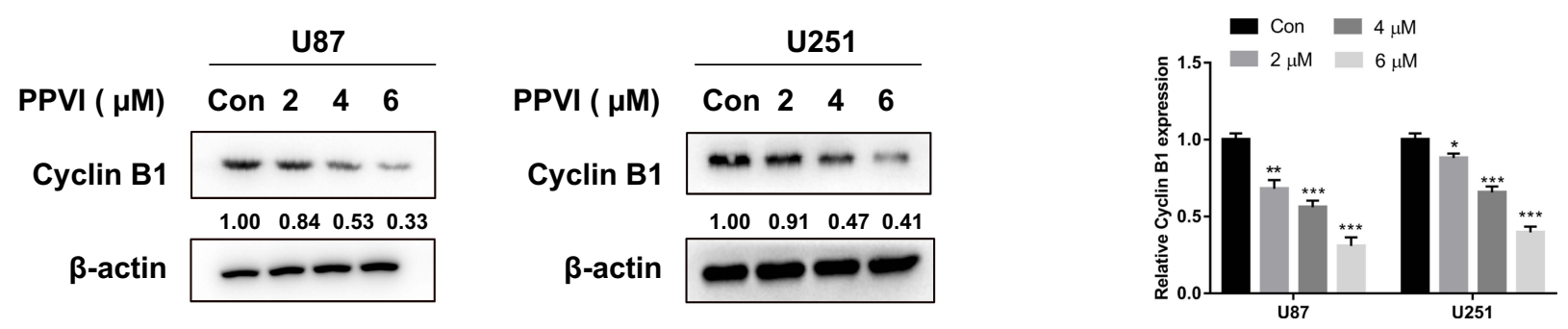

Figure 3 PPVI induced cell cycle arrest in glioma cells. (A) Cell cycle distribution was measured via flow cytometry in cells treated with the indicated concentrations of PPVI for 24 h. (B) The Cyclin BI was detected by Western blot. * $\mathrm{p}<0.05$, ** $\mathrm{P}<0.01$, *** $\mathrm{p}<0.001$.

0.0001 ) in $\mathrm{U} 251$, relative to controls. On the other hand, pretreatment with $20 \mu \mathrm{M}$ of $\mathrm{z}-\mathrm{VAD}$ attenuated the cell death triggered by PPVI in U87 $(71.5 \pm 4.03 \%, \mathrm{p}=0.0185)$ and U251 (74.6 $\pm 3.68 \%, p=0.0116)$ (Figure 4C). These results were also confirmed by flow cytometry (Figure 4D). Taken together, these data showed that PPVI played a role in hindering the proliferative activity of glioma cells by provoking apoptosis.

\section{PPVI Triggers Autophagy in Glioma Cells}

Exposure of glioma cells to varying concentrations of PPVI resulted in an increase in LC3-II, marker of autophagy (Figure 5A). Another autophagy-related protein, Beclin-1, was also upregulated in PPVI-treated glioma cells, suggesting a possible role by PPVI in inducing autophagy in glioma cells.

Next, we tested the ability of 3-MA, an autophagy inhibitor, to limit the PPVI-induced autophagy in U251 and U87 and found that $3 \mathrm{mM} 3-\mathrm{MA}$ enhanced cell death triggered by PPVI $(4 \mu \mathrm{M})$ in U87 $(47.8 \pm 2.53 \%, \mathrm{p}=0.027)$ and $\mathrm{U} 251$ $(41.6 \pm 2.09 \%, \mathrm{p}=0.010)$ (Figure 5B). Meanwhile, 3-MA upregulated the apoptosis-related proteins and increased the proportion of apoptotic cells in U87 (39.1 $\pm 2.94 \%$, $\mathrm{p}=0.006)$ as well as U251 (45.6 $\pm 4.03 \%, \mathrm{p}=0.0141)$ (Figure 5C and D). This suggests that PPVI-induced autophagy might promote the survival of glioma cells.

\section{PPVI Increases ROS Production and Activates JNK and P38 Pathways}

Previous studies suggest that excessive ROS production can induce both apoptosis and autophagy. ${ }^{14,20,21}$ Excess ROS production can upregulate apoptosis-related proteins and induce apoptosis. Based on this hypothesis, we investigated the association between PPVI treatment and ROS production in glioma cells using DCFH-DA, a fluorescence probe. Compared with the control group, we found a significant increase in intracellular ROS levels in response to PPVI in U87 $(1.1 \pm 0.19$ vs $5.7 \pm 0.76$ vs $15.2 \pm 0.86$ vs $27.2 \pm 1.68$, $\mathrm{p}<0.0001$ for the 3 groups $)$ and U251 $(0.9 \pm 0.17 \%$ vs $6.2 \pm$ 0.74 vs $14.7 \pm 1.15$ vs $32.7 \pm 2.41, \mathrm{p}<0.0001$ for the 3 groups (Figure 6A)). Furthermore, immunofluorescence indicated that $10 \mathrm{mM}$ NAC, an ROS scavenger, was enough to hinder ROS production (Figure 6B). The results were further confirmed by flow cytometry. On the other hand, 10 mM NAC could reverse generation of ROS, which had initially been triggered by PPVI $(4 \mu \mathrm{M})$ in U87 
A

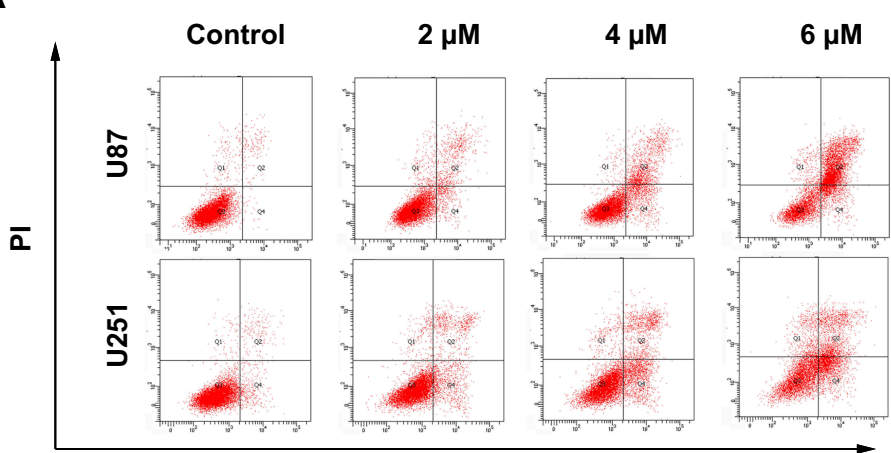

Annexin V-FITC

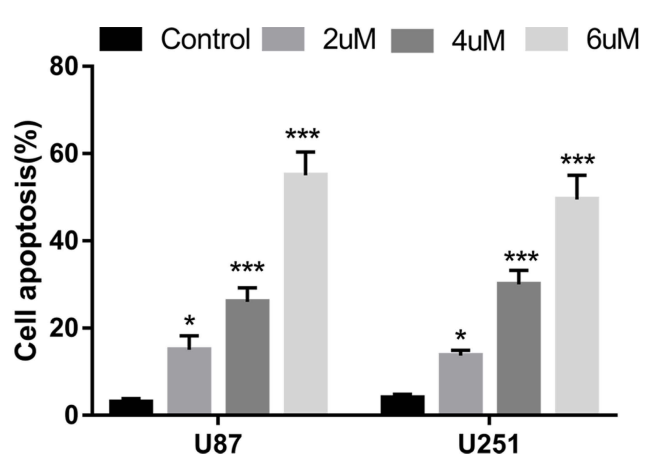

C

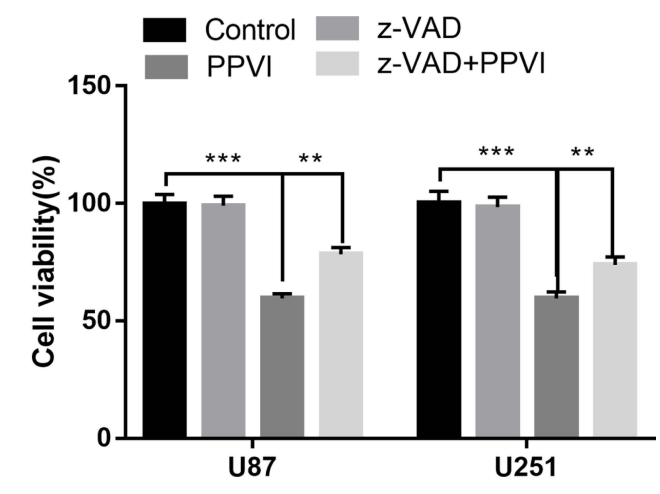

D

\begin{tabular}{|c|c|c|c|c|}
\hline \multirow[b]{2}{*}{ PPVI $(\mu \mathrm{M})$} & \multicolumn{4}{|c|}{ U87 } \\
\hline & Con & 2 & 4 & 6 \\
\hline \multirow[t]{2}{*}{ Cle-cap.3 } & - & - & - & - \\
\hline & 1.00 & 01.21 & 1.35 & 51.55 \\
\hline \multirow[t]{2}{*}{ Cle-cap.8 } & - & - & - & - \\
\hline & 1.00 & 01.27 & 1.45 & 1.98 \\
\hline \multirow[t]{2}{*}{ Cle-cap.9 } & - & - & - & - \\
\hline & 1.00 & 01.31 & 1.63 & 1.89 \\
\hline \multirow[t]{2}{*}{ Bcl-2 } & - & - & - & - \\
\hline & 1.00 & 0.88 & 0.54 & 0.32 \\
\hline \multirow[t]{2}{*}{ Bax } & - & - & - & - \\
\hline & 1.00 & 01.20 & 1.43 & 1.77 \\
\hline$\beta$-actin & - & - & - & - \\
\hline
\end{tabular}

U251

Con $2 \quad 4 \quad 6$

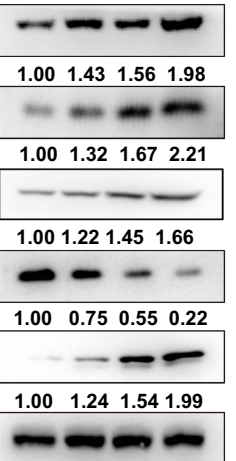

\section{Control}

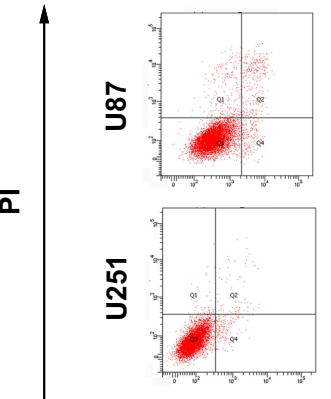

Z-VAD
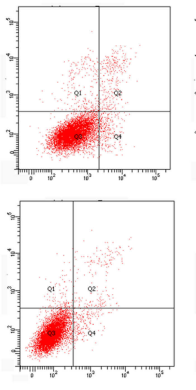

PPVI

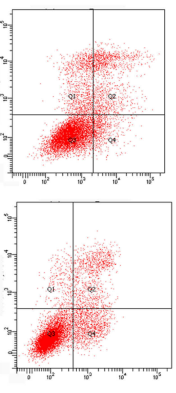

PPVI_z-VAD
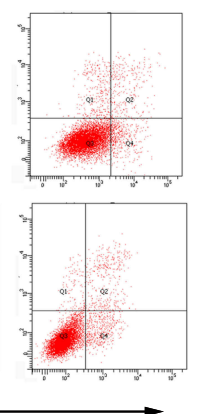

Annexin V-FITC

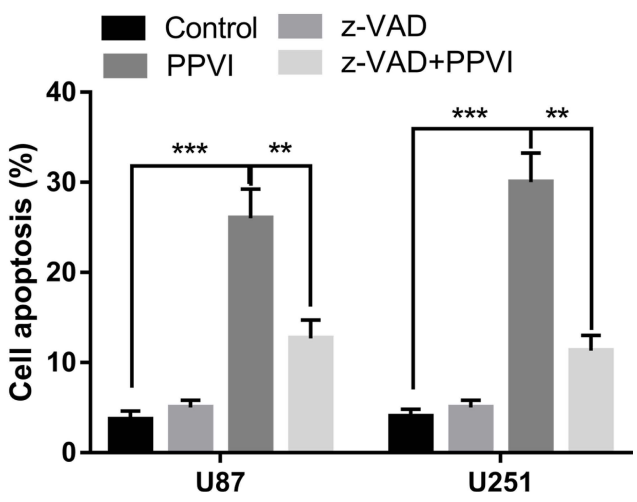

Figure 4 Apoptosis was induced by PPVI in glioma cells. Cells were treated with the indicated concentrations of PPVI for 24 hrs. (A) The apoptotic cells were detected via flow cytometry. (B) The expressions of Bcl-2, Bax and cleaved-caspase-3, -8 , and -9 were analyzed by Western blot. Cells were pre-incubated with z-VAD (20 $\mu \mathrm{M})$ for 2 hrs and then treated with PPVI $(4 \mu \mathrm{M})$ for $24 \mathrm{~h}$. (C) The CCK-8 assay was used to assess glioma cell viability. (D) Apoptotic cells were detected using flow cytometry. * $<0.05$, $* * \mathrm{p}<0.01$, *** $\mathrm{p}<0.001$.

Abbreviations: z-VAD, Z-VAD-FMK; cle-cap.3, cleaved caspase-3; cle-cap.8, cleaved caspase-8; cle-cap.9, cleaved caspase-9.

$(4.9 \pm 0.55, \mathrm{p}=0.013)$ and $\mathrm{U} 251(4.5 \pm 0.47, \mathrm{p}=0.018)$ (Figure 6C-E). SP600125 (SP) is tan inhibitor of JNK and SB203580 (SB) which inhibits p38. Levels of ROS, after treatment of SP $(20 \mu \mathrm{M})$ and SB $(20 \mu \mathrm{M})$, were not significantly altered (Figure S1 A, and $\underline{\text { B) }}$. These data demonstrated the ability of PPVI to induce ROS generation in glioma cells.

To understand whether PPVI could modulate JNK and p38 pathways, we performed a Western blot analysis and found that treatment of glioma cells with this compound triggered 
A

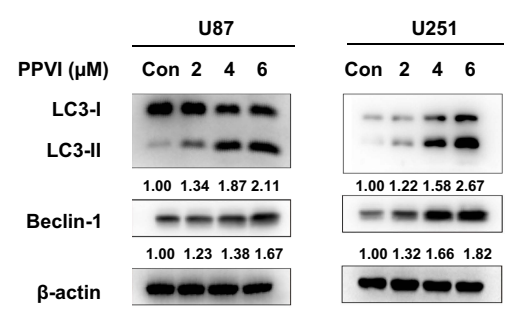

B

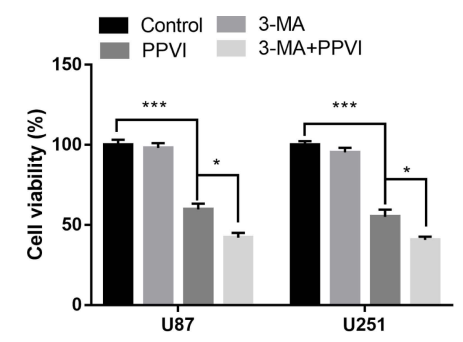

C

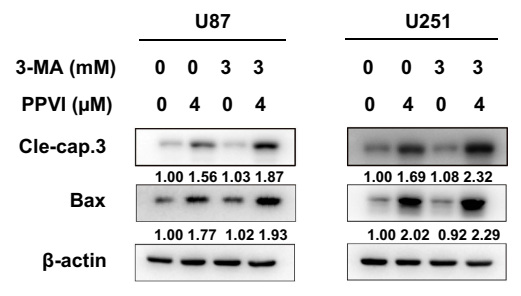

D
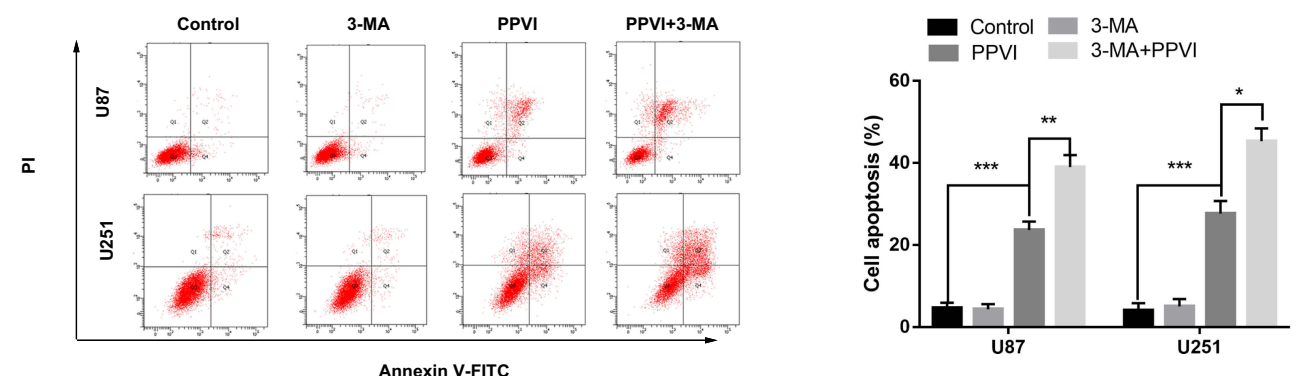

Figure 5 PPVI induced autophagy and restriction of autophagy promoted PPVI-induced apoptosis. (A) LC3 and Beclin-I expressions were examined by Western blot analysis. Cells were pre-treated with or without 3-MA (3 mM) for 2 hrs, followed by PPVI $(4 \mu \mathrm{M})$ treatment for an additional 24 h. (B) CCK-8 assay was used to assess glioma cell viability. (C) Apoptosis-related proteins Bax and cleaved-caspase-3 were analyzed by Western blot analysis. (D) Apoptotic cells were detected by flow cytometry. $* \mathrm{p}<0.05$, ** $\mathrm{p}<0.01$, *** $\mathrm{p}<0.001$.

Abbreviations: 3-MA, 3-methyladenine.

activation of JNK and p38 (Figure 6F). These were, however, reversed following the pretreatment of the cells with NAC (Figure 7C). PPVI could, therefore, provoke the JNK and p38 pathways via the accumulation of ROS.

\section{PPVI Triggers Cell Cycle Arrest, Autophagy and Apoptosis Through ROS-Mediated JNK and P38 Phosphorylation}

To determine whether PPVI-induced cell cycle arrest, autophagy and apoptosis are dependent on ROS-mediated JNK and $\mathrm{p} 38$ activation, we analyzed NAC (an ROS scavenger) as well as SP and SB (inhibitors of JNK and p38, respectively). Results from the CCK-8 assay indicated that $10 \mathrm{mM}$ NAC, $20 \mu \mathrm{M}$ SP and $20 \mu \mathrm{M}$ SB successfully reversed PPVIinduced cell growth inhibition (Figure S2). Flow cytometric analysis revealed that treatment with $4 \mu \mathrm{M}$ PPVI increased the percentage of apoptotic cells by $26.7 \pm 1.25 \%(\mathrm{p}<0.001)$ while pretreatment with NAC $(10 \mathrm{mM}), \mathrm{SP}(20 \mu \mathrm{M})$ and SB $(20 \mu \mathrm{M})$ could successfully reverse PPVI-induced apoptosis by $14.7 \pm 2.05 \%(\mathrm{p}=0.0021), 19.3 \pm 2.62 \%(\mathrm{p}=0.0239)$, and $18.3 \pm 2.49 \%(\mathrm{p}=0.0134)$, respectively (Figure 7A). PPVI (4 $\mu \mathrm{M})$ treatment further induced $\mathrm{G} 2 / \mathrm{M}$ phase arrest $(25.8 \pm$ $2.33 \%, \mathrm{p}<0.0001)$, whereas NAC $(10 \mathrm{mM})$, SP $(20 \mu \mathrm{M})$ and
SB $(20 \mu \mathrm{M})$ could reverse the effect by $15.3 \pm 1.33 \%(\mathrm{p}=$ $0.0022), 18.7 \pm 1.52 \%(\mathrm{p}=0.0110)$, and $17.8 \pm 1.45 \%(\mathrm{p}=$ 0.0106), respectively (Figure 7B). Notably, NAC had more potent effects compared to SP and SB. We further investigated whether the generation of ROS and the activation of JNK and p38 were involved in PPVI-triggered autophagy and apoptosis and found that pretreatment of cells with NAC $(10 \mathrm{mM})$, SP $(20 \mu \mathrm{M})$ and SB $(20 \mu \mathrm{M})$ inhibited levels of apoptosis-related (cleaved caspase-3 and Bax) as well as autophagy-related proteins (LC3-II and Beclin-1) (Figure 7C). Taken together, these data indicated that PPVI successfully triggers cell cycle arrest, autophagy, as well as apoptosis by activating ROS-mediated JNK and p38 pathways.

\section{PPVI Inhibits Tumor Growth in vivo}

We investigated the antitumor effects of PPVI in vivo using a model generated by subcutaneously injecting U87 cells into mice. Mice treated with PPVI $(5 \mathrm{mg} / \mathrm{kg})$ showed significantly reduced tumor volumes $\left(574.4 \pm 84.02 \mathrm{~mm}^{3}\right.$ vs $286.68 \pm$ $\left.34.89 \mathrm{~mm}^{3}, \mathrm{p}=0.0003\right)$ and weight $(0.43 \pm 0.023 \mathrm{~g}$ vs $0.19 \pm$ $0.031 \mathrm{~g}, \mathrm{p}=0.0003$ ) relative to controls (Figure $8 \mathrm{~A}-\mathrm{C}$ ). We did not observe alterations in body weight during the experiment (Figure 8D), suggesting that PPVI had limited side effects in vivo. To assess whether PPVI inhibited tumor 
A

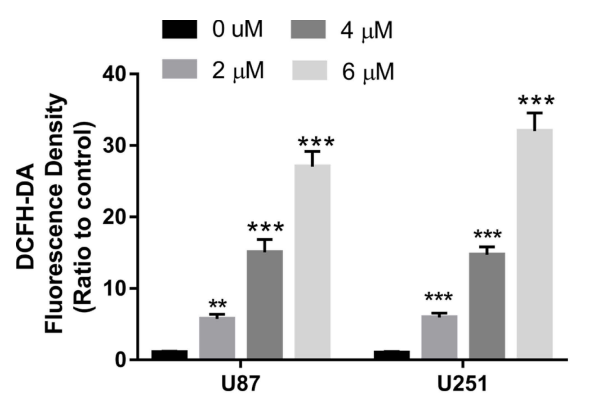

C

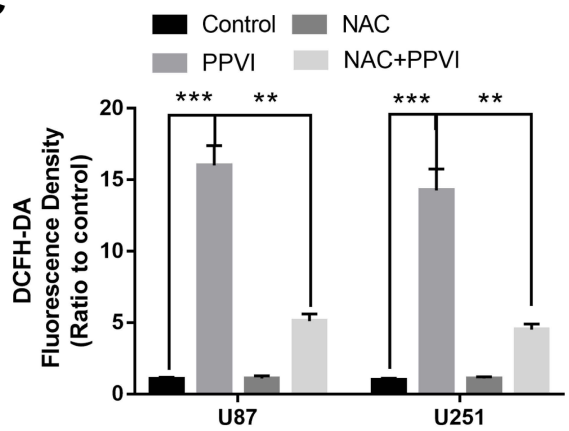

$\mathbf{F}$

U87

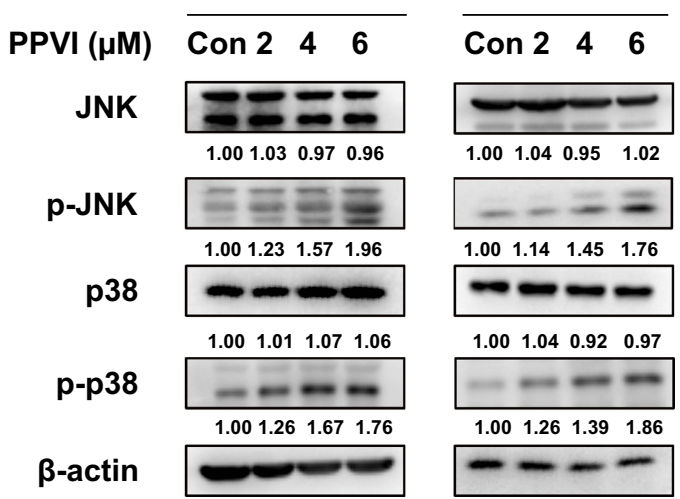

B

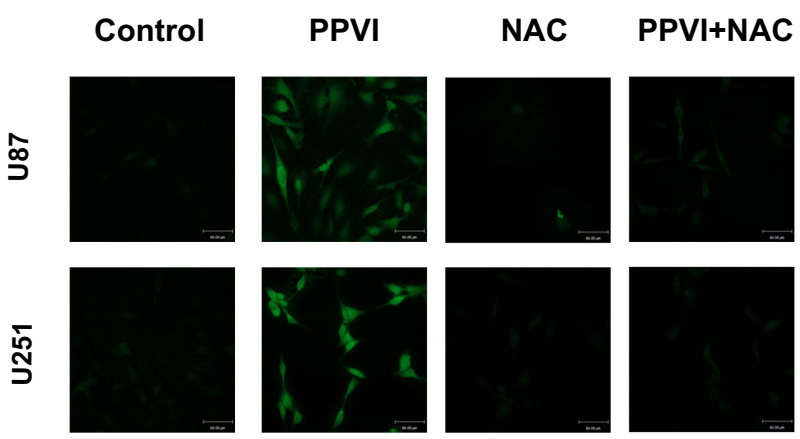

D

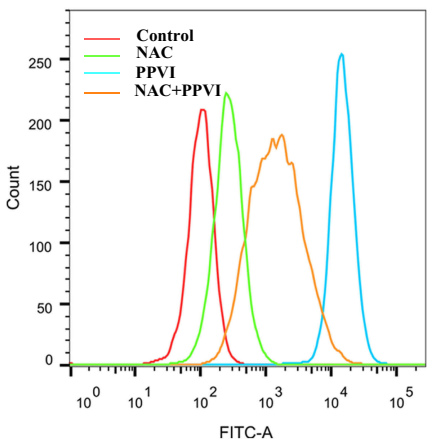

U87
E

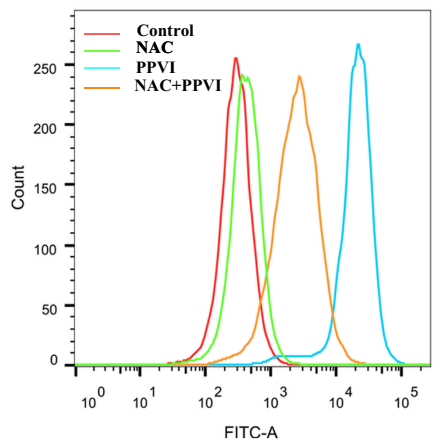

U251

Figure 6 PPVI induced overproduction of intracellular ROS and promotes JNK and p38 phosphorylation in glioma cells. (A) Cells were treated with various concentrations of PPVI for 24 hrs and then incubated with $5 \mu$ M DCFH-DA. (B-E) Cells were pre-treated with or without NAC (I0 mM) for 2 hrs followed by PPVI (4 $\mu$ M) treatment for an additional $24 \mathrm{hrs}$ and then stained with $5 \mu \mathrm{M}$ DCFH-DA. The levels of ROS were detected using fluorescence microscopy and flow cytometry. The mean DCFH-DA fluorescence was shown in histograms. (F) Cells were incubated with the indicated concentrations of PPVI for 24 hrs. The expressions of P-p38, p38, P-JNK, and JNK were evaluated by Western blot analysis. * $\mathrm{p}<0.05$, ** $\mathrm{p}<0.01$, *** $\mathrm{p}<0.001$.

Abbreviations: NAC, $\mathrm{N}$-acetyl cysteine.

growth by inhibiting cell proliferation, we performed immunohistochemistry for Ki67 in tumor sections and found a remarkable decrease in expression of this factor the PPVI treatment relative to the control group $(53.2 \pm 3.61 \%$ vs 14.6 $\pm 1.3 \%, \mathrm{p}=0.0007$ ) (Figure 8E). This indicates that PPVI mediated a decrease in Ki67 expression in U87 xenograft tumors.

\section{Discussion}

Glioma is an aggressive tumor that results in high mortality. Limited treatment options are available for this condition, necessitating the development of novel and effective therapeutic strategies. Surprisingly, many agents isolated from natural plants demonstrated potential anticancer effects through various mechanisms. For instance, Zhang et $\mathrm{al}^{22}$ 


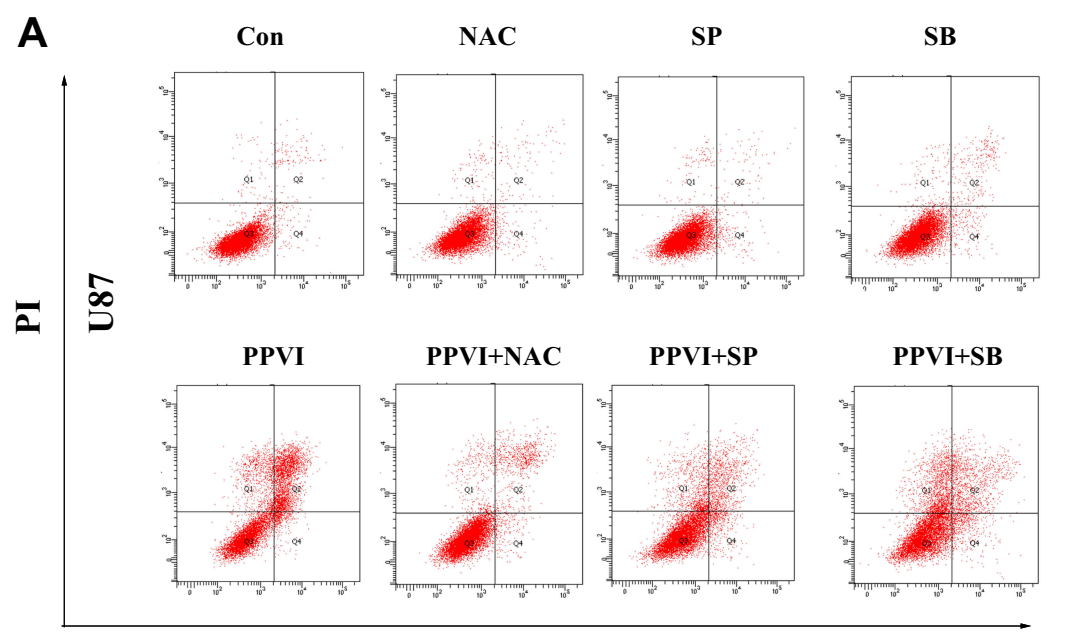

\section{Annexin V-FITC}

B
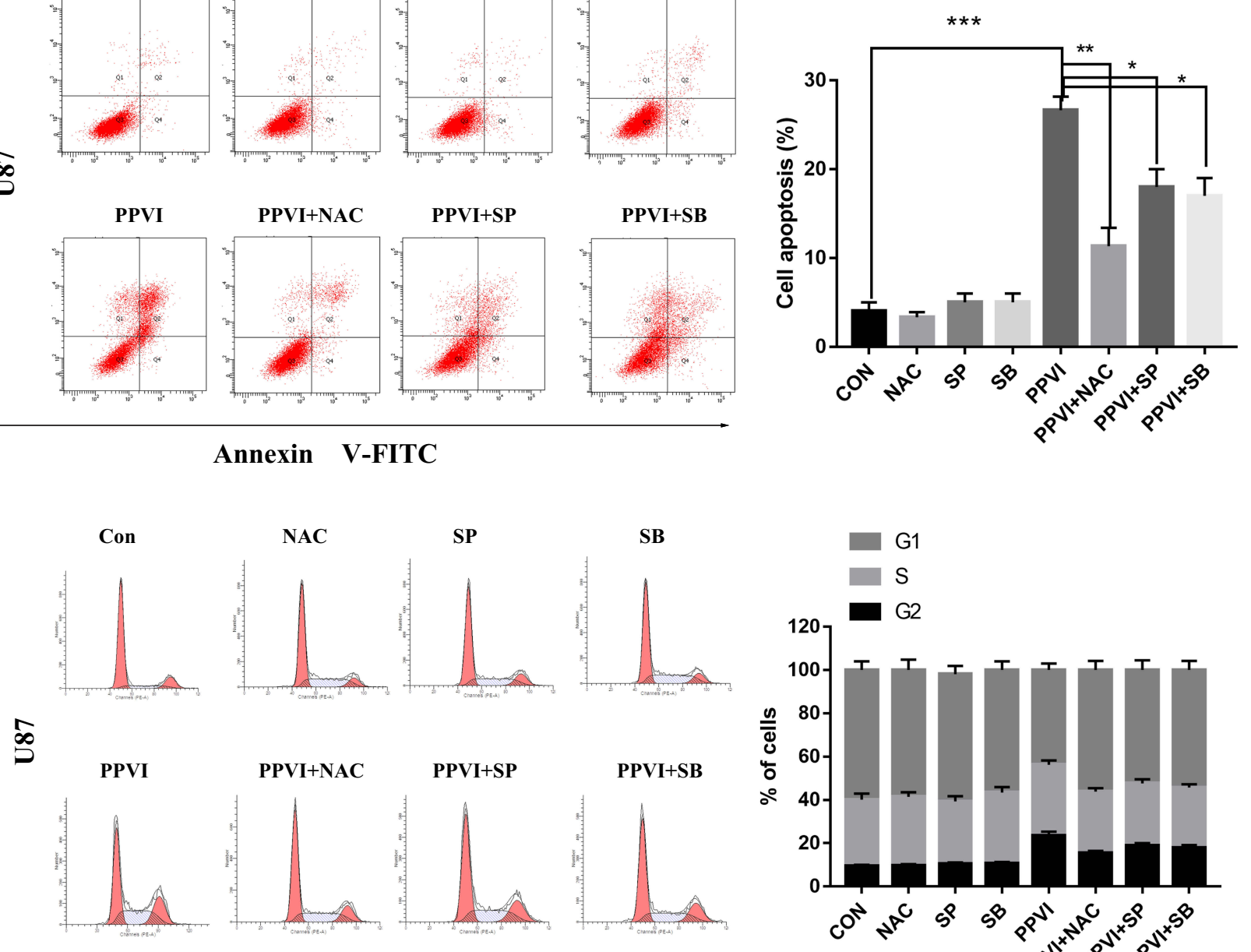

C
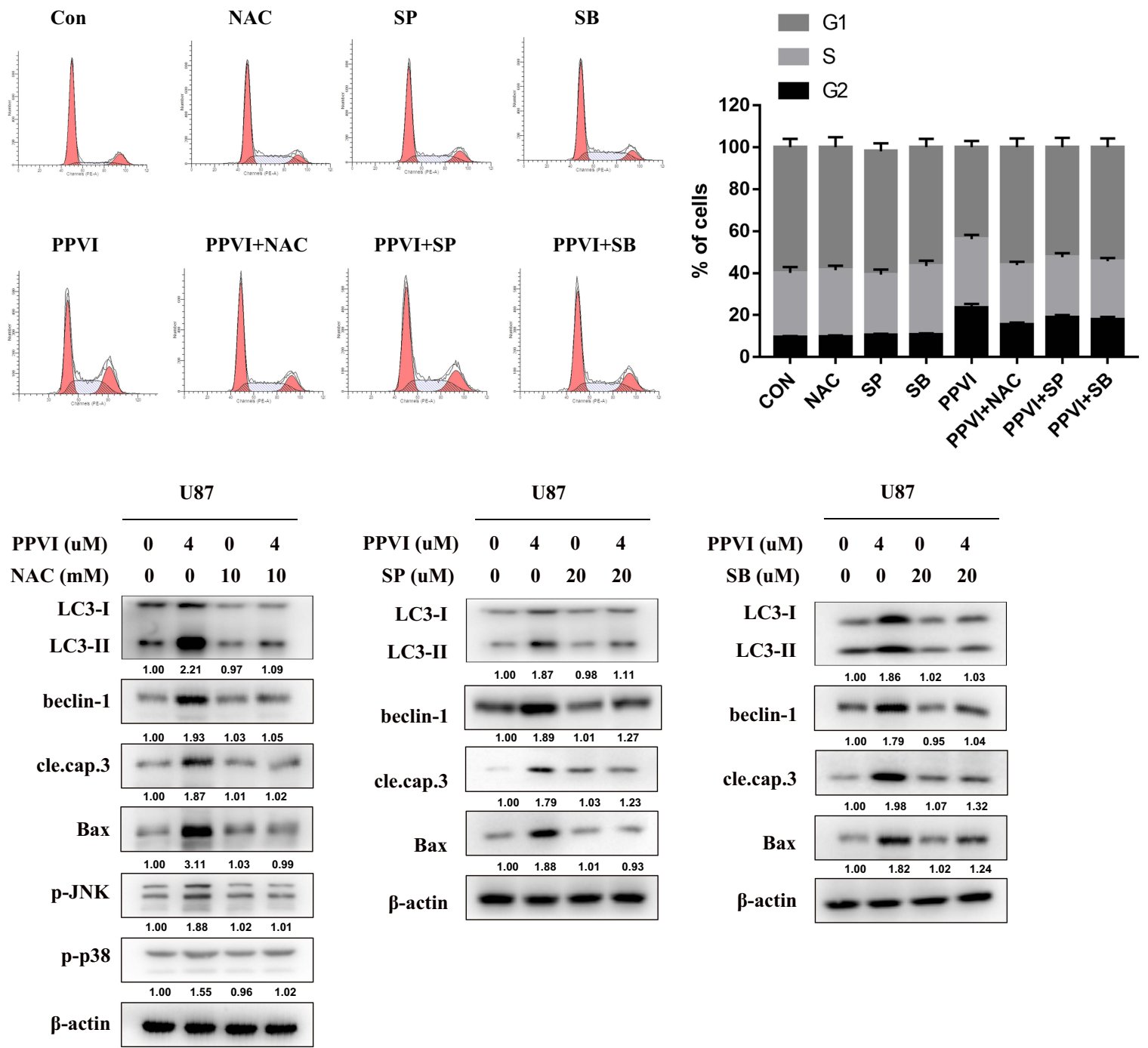

Figure 7 The JNK and p38 pathways triggered by ROS mediate PPVI-provoked cell cycle arrest, apoptosis and autophagy. (A) Apoptotic cells were measured by flow cytometry. (B) Cell cycle distribution percentages were evaluated via flow cytometry. (C) The autophagy-related proteins, apoptosis-related proteins and phospho-JNK and phospho-p38 were analyzed using Western blot. ${ }^{*} \mathrm{p}<0.05$, $* * \mathrm{p}<0.01,{ }^{*} * \mathrm{p}<0.001$.

Abbreviations: NAC, N-acetyl cysteine; SP, SP600 I25; SB, SB203580. 
A

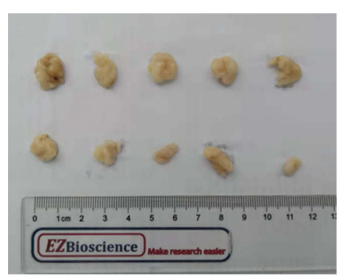

D

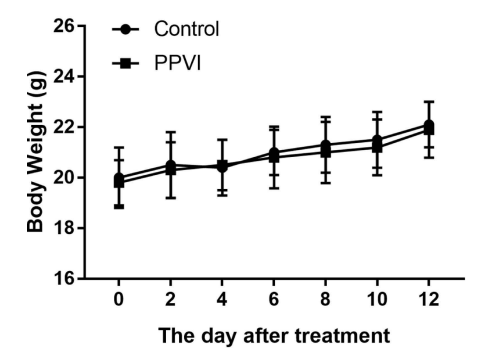

B

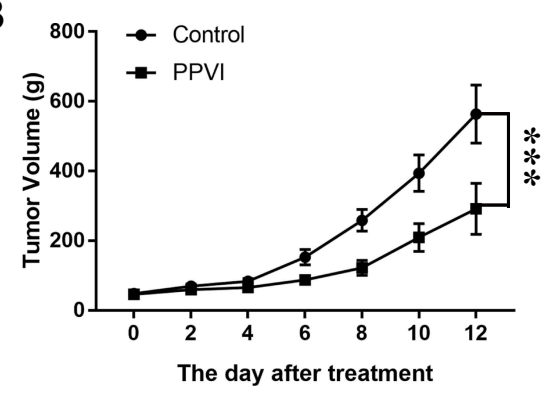

E

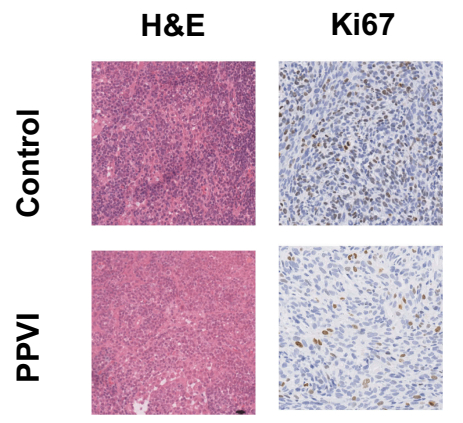

C

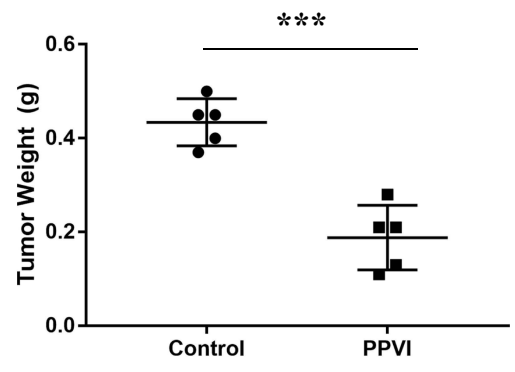

Figure 8 PPVI inhibits glioma xenograft growth in vivo. (A) Representative images of tumors harvested from nude mice. (B) Tumor volume was measured every 2 days. (C) Tumor weight was detected after mice were euthanized (D) Body weights were measured every 2 days. (E) H\&E staining was used to evaluate the histology of tumor sections and immunohistochemical analysis was employed to detect the expression of Ki67. $* * * \mathrm{p}<0.00 \mathrm{I}$ versus the control group.

reported that Isoliensinine, isolated from the seed embryo of lotus, could hinder the growth of human breast cancer cells through ROS generation. In glioma, Celastrol has been reported to inhibit human glioma by mediating autophagy and apoptosis. ${ }^{15}$ In the current study, we describe the ability of PPVI, the main active ingredient extracted from Paris polyphylla, to exhibit cytotoxicity in various malignancies. ${ }^{6,20,23,24}$ We reveal the anti-tumor effects of this compound, in the suppression of cell proliferation and migration, blocking cell cycle progression as well as the induction of autophagy and apoptosis. Furthermore, we show that the anti-tumor activity of PPVI in glioma cells function through the accumulation of ROS and activation of the JNK and p38 pathways.

Generally, cancer cells are characterized by an abnormally regulated cell cycle, which is mainly attributed to alterations in the structure and function of cyclins and cyclindependent kinases. Studies targeting cell cycle checkpoints have been the focus of many researchers aimed at developing treatment approaches for several malignancies. ${ }^{9,25}$ In fact, recent studies have demonstrated that a fraction of Paris polyphylla exhibited anti-cancer properties by inducing G2/ $\mathrm{M}$ cell cycle arrest in a variety of tumors. For example, PPVI and PPVII were found to suppress the proliferation of lung cancer cells by causing G2/M phase arrest. ${ }^{26}$ Just like in these studies, the findings of this study demonstrated that PPVI can induce a G2/M arrest in glioma and downregulate cyclin B1 levels, indicating that it restricts cell proliferation by affecting cell cycle progression. However, the mechanisms underlying this phenomenon remain to be unraveled.

Apoptosis occurs through the extrinsic and the intrinsic pathways. ${ }^{27,28}$ The exogenous apoptosis pathway is initiated by Caspase-8, with its activation leading to subsequent downstream cascade reactions. ${ }^{29}$ In the intrinsic pathway, cells triggered by intracellular stimuli through the $\mathrm{Bcl}-2$ protein family activate caspase-9 and caspase-3. ${ }^{30,31}$ In the present study, PPVI induced apoptosis in osteosarcoma cells by activating apoptosis pathways. Our data revealed that treatment of cells with PPVI increased expression of Bax, cleaved caspase-3, 8, and 9, and reduced Bcl-2 in glioma cells, confirming the occurrence of apoptosis. To further verify these results, analysis of the pan-caspase inhibitor z-VAD showed that this factor could partly inhibit apoptotic cell death triggered by PPVI. Taken together, these data demonstrated that PPVI induced apoptosis in glioma cells.

Autophagy is a complex biological process, that involves initiation, autophagy formation, lysosomal production, autophagy lysosomal fusion and degradation. ${ }^{32,33} \mathrm{LC} 3-\mathrm{II}$ is the most 
commonly recognized marker for autophagy and therefore a reliable method for monitoring the process. ${ }^{34,35}$ Beclin-1 was the first identified mammalian factor that could mediate autophagy and is also the upstream molecule required for autophagosome formation. ${ }^{36}$ In the current study, elevated levels of LC3-II and Beclin-1 indicated that PPVI could successfully induce autophagy in glioma cells. According to previous studies, many natural compounds have been reported to trigger both apoptosis and autophagy in tumor cells. ${ }^{15,25}$ However, the complex interactions between the two processes seem rather different. For example, Wang et $\mathrm{al}^{25}$ found that blocking Erianin-induced autophagy could enhance its apoptotic effect on human osteosarcoma cells, while Tian et $\mathrm{al}^{37}$ reported that inhibition of autophagy could reverse PPI induced-apoptosis. In our study, we used 3-MA to inhibit autophagy and found enhancement of PPVI-induced apoptosis indicating that autophagy induced by PPVI might promote cell survival. However, further studies are required to detect the molecular mechanisms regulating apoptosis and autophagy.

ROS play a crucial role in tumorigenesis, with accumulating evidence suggesting that excessive production of ROS directly causes DNA damage and leads to apoptosis. ${ }^{38,39}$ Consequently, targeting ROS has been considered a promising strategy for anti-tumor therapy, since it can stimulate or inhibit different cell signaling pathways to induce apoptosis and autophagy thereby inhibit tumor growth. ${ }^{40,41}$ Additionally, high levels of ROS can induce cell cycle arrest. In the present study, PPVI-induced cell death paralleled the levels of ROS. Furthermore, NAC, an ROS scavenger, remarkably reversed the effects by reducing the production of ROS. This suggests that PPVI induces ROS accumulation leading to the death of glioma cells.

In the recent past, growing evidence has that ROS production is directly associated with MAPK activation,

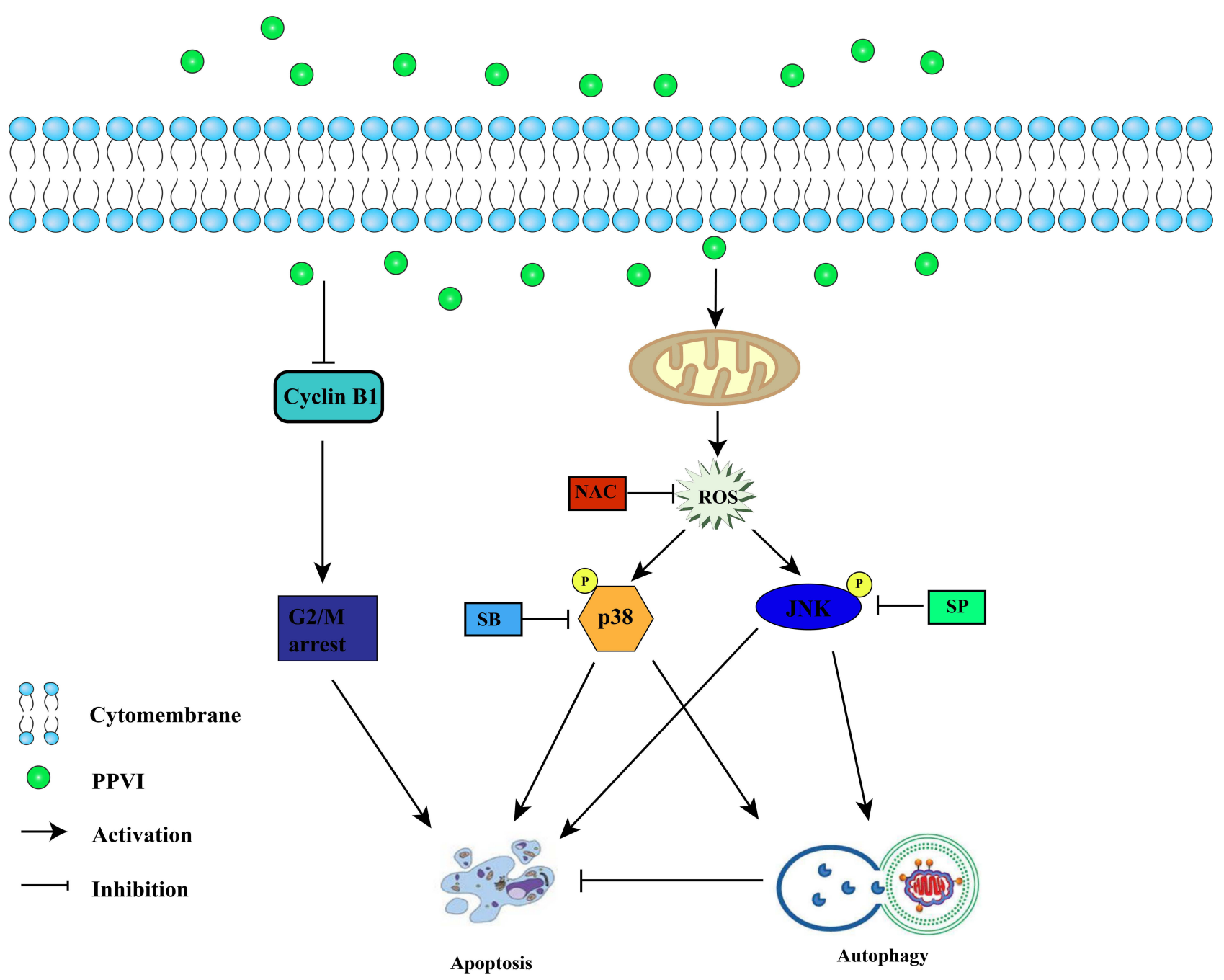

Figure 9 Hypothetical schema of PPVI-induced apoptosis and autophagy in glioma cells. 
especially JNK and p38, which induce cell apoptosis and autophagy. ${ }^{42,43}$ In fact, numerous studies have shown that many natural compounds can induce cell apoptosis and autophagy in tumors by activating JNK and p38. In this study, we found that PPVI could activate the JNK and p38 pathways, consistent with previous studies. ${ }^{6,20}$ Furthermore, SP and SB partially attenuated the PPVIinduced effects on glioma cells, and NAC treatment attenuated JNK and p38 activation induced by PPVI. However, the levels of ROS, after SP and SB treatment, did not show an obvious change indicating that ROS could modulate the JNK and p38 pathways. Collectively, our findings provide preliminary evidence to indicate that blocking of cell cycle progression and induction of apoptosis as well as autophagy, provoked by PPVI, might be attributed to ROS-modulated JNK and p38 pathways.

\section{Conclusions}

Our findings show that PPVI hindered the growth of glioma cells by arresting the cell cycle and inducing apoptosis and autophagy. Furthermore, ROS production, as well as JNK and p38 phosphorylation are required in blocking of cell cycle progression and triggering autophagy and apoptosis. We also showed that PPVI effectively restrained tumor growth in xenograft models in vivo without obvious toxicity. Overall, PPVI may be a novel candidate for the development of antitumor drugs against glioma (Figure 9).

\section{Ethical Approval}

All experiments involving mice were approved by the Cancer Hospital, Chinese Academy of Medical Sciences, Experimental Animal Ethics Committee and followed the Institutional Animal Welfare Guidelines issued by Chinese Academy of Medical Sciences.

\section{Acknowledgments}

This work was supported by funding from the National Key R\&D Program of China (2018YFC1313101), National Natural Science Foundation of China (No. 81872398) and we thank Dr Jerry, from free science group, for editing the English text of a draft of this manuscript.

\section{Disclosure}

The authors declare no conflicts of interest in this work.

\section{References}

1. Liu Y, Shete S, Hosking F, Robertson L, Houlston R, Bondy M. Genetic advances in glioma: susceptibility genes and networks. Curr Opin Genet Dev. 2010;20(3):239-244. doi:10.1016/j.gde.2010.02.001

2. Lapointe S, Perry A, Butowski NA. Primary brain tumours in adults. Lancet. 2018;392(10145):432-446. doi:10.1016/S0140-6736(18) 30990-5

3. Louvel G, Metellus P, Noel G, et al. Delaying standard combined chemoradiotherapy after surgical resection does not impact survival in newly diagnosed glioblastoma patients. Radiother Oncol. 2016;118 (1):9-15. doi:10.1016/j.radonc.2016.01.001

4. Chen R, Smith-cohn M, Cohen AL, Colman H. Glioma subclassifications and their clinical significance. Neurotherapeutics. 2017;14 (2):284-297. doi:10.1007/s13311-017-0519-x

5. Mrugala MM. Bevacizumab for recurrent malignant gliomas: efficacy, toxicity, and patterns of recurrence. Neurology. 2009;72(8):773. (). doi:10.1212/WNL.0b013e3181a9fad1

6. Teng JF, Qin DL, Mei QB, et al. Polyphyllin VI, a saponin from Trillium tschonoskii Maxim. induces apoptotic and autophagic cell death via the ROS triggered mTOR signaling pathway in non-small cell lung cancer. Pharmacol Res. 2019;147:104396. doi:10.1016/j. phrs.2019.104396

7. Liu Y, Dong X, Wang W, et al. Molecular mechanisms of apoptosis in HepaRG cell line induced by polyphyllin VI via the Fas death pathway and mitochondrial-dependent pathway. Toxins. 2018;10(5):201. doi:10.3390/toxins 10050201

8. Cannell IG, Merrick KA, Morandell S, et al. A pleiotropic RNA-binding protein controls distinct cell cycle checkpoints to drive resistance of p53-defective tumors to chemotherapy. Cancer Cell. 2015;28(6):831. doi:10.1016/j.ccell.2015.11.003

9. Wang Z, Fan M, Candas D, et al. Cyclin B1/Cdk1 coordinates mitochondrial respiration for cell-cycle G2/M progression. Dev Cell. 2014;29(2):217-232. doi:10.1016/j.devcel.2014.03.012

10. Zimmermann KC, Bonzon C, Green DR. The machinery of programmed cell death. Pharmacol Ther. 2001;92(1):57-70. doi:10.1016/S0163-7258(01)00159-0

11. Wang RC, Wei Y, An Z, et al. Akt-mediated regulation of autophagy and tumorigenesis through Beclin 1 phosphorylation. Science. 2012;338(6109):956-959. doi:10.1126/science. 1225967

12. Li-weber M. Targeting apoptosis pathways in cancer by Chinese medicine. Cancer Lett. 2013;332(2):304-312. doi:10.1016/j. canlet.2010.07.015

13. Amaravadi RK, Lippincott-schwartz J, Yin XM, et al. Principles and current strategies for targeting autophagy for cancer treatment. Clin Cancer Res. 2011;17(4):654-666. doi:10.1158/1078-0432.CCR-10-2634

14. Degenhardt K, Mathew R, Beaudoin B, et al. Autophagy promotes tumor cell survival and restricts necrosis, inflammation, and tumorigenesis. Cancer Cell. 2006;10(1):51-64. doi:10.1016/j. ccr.2006.06.001

15. Liu X, Zhao P, Wang X, et al. Celastrol mediates autophagy and apoptosis via the ROS/JNK and Akt/mTOR signaling pathways in glioma cells. J Exp Clin Cancer Res. 2019;38(1):184. doi:10.1186/ s13046-019-1173-4

16. Pereira L, Igea A, Canovas B, Dolado I, Nebreda AR. Inhibition of p38 MAPK sensitizes tumour cells to cisplatin-induced apoptosis mediated by reactive oxygen species and JNK. EMBO Mol Med. 2013;5(11):1759-1774. doi:10.1002/emmm.v5.11

17. Kumar D, Shankar S, Srivastava RK. Rottlerin induces autophagy and apoptosis in prostate cancer stem cells via PI3K/Akt/mTOR signaling pathway. Cancer Lett. 2014;343(2):179-189. doi:10.1016/ j.canlet.2013.10.003

18. Li HY, Zhang J, Sun LL, et al. Celastrol induces apoptosis and autophagy via the ROS/JNK signaling pathway in human osteosarcoma cells: an in vitro and in vivo study. Cell Death Dis. 2015;6(1) e1604. doi:10.1038/cddis.2014.543 
19. Wu Z, Zhang J, Xu F, Wang Y, Zhang J. Rapid and simple determination of polyphyllin I, II, VI, and VII in different harvest times of cultivated Paris polyphylla Smith var. yunnanensis (Franch.) Hand.-Mazz by UPLC-MS/MS and FT-IR. J Nat Med. 2017;71 (1):139-147. doi:10.1007/s11418-016-1043-8

20. Yuan YL, Jiang N, Li ZY, et al. Polyphyllin VI induces apoptosis and autophagy in human osteosarcoma cells by modulation of ROS/JNK activation. Drug Des Devel Ther. 2019;13:3091-3103. doi:10.2147/ DDDT.S194961

21. Zhu J, Yu W, Liu B, et al. Escin induces caspase-dependent apoptosis and autophagy through the ROS/p38 MAPK signalling pathway in human osteosarcoma cells in vitro and in vivo. Cell death dis. 2017;8 (10):e3113.

22. Zhang $\mathrm{X}$, Wang $\mathrm{X}, \mathrm{Wu} \mathrm{T}$, et al. Isoliensinine induces apoptosis in triple-negative human breast cancer cells through ROS generation and p38 MAPK/JNK activation. Sci Rep. 2015;5(1):12579. doi: $10.1038 /$ srep 12579

23. Wang P, Yang Q, Du X, Chen Y, Zhang T. Targeted regulation of Rell2 by microRNA-18a is implicated in the anti-metastatic effect of polyphyllin VI in breast cancer cells. Eur $J$ Pharmacol. 2019;851:161-173. doi:10.1016/j.ejphar.2019.02.041

24. Wang W, Dong X, You L, et al. Apoptosis in HepaRG and HL-7702 cells inducted by polyphyllin II through caspases activation and cell-cycle arrest. $J$ Cell Physiol. 2019;234(5):7078-7089. doi: $10.1002 /$ jcp. 27462

25. Wang H, Zhang T, Sun W, et al. Erianin induces G2/M-phase arrest, apoptosis, and autophagy via the ROS/JNK signaling pathway in human osteosarcoma cells in vitro and in vivo. Cell Death Dis. 2016;7(6):e2247. doi:10.1038/cddis.2016.138

26. Lin Z, Liu Y, Li F, et al. Anti-lung cancer effects of polyphyllin VI and VII potentially correlate with apoptosis in vitro and in vivo. Phytother Res. 2015;29(10):1568-1576.

27. Guo Z, Guozhang H, Wang H, Li Z, Liu N. Ampelopsin inhibits human glioma through inducing apoptosis and autophagy dependent on ROS generation and JNK pathway. Biomed Pharmacother. 2019;116:108524. doi:10.1016/j.biopha.2018.12.136

28. Wang F, Tian X, Zhang Z, et al. Demethylzeylasteral (ZST93) inhibits cell growth and enhances cell chemosensitivity to gemcitabine in human pancreatic cancer cells via apoptotic and autophagic pathways. Int J Cancer. 2018;142(9):1938-1951. doi:10.1002/ijc. v142.9

29. Fianco G, Contadini C, Ferri A, Cirotti C, Stagni V, Barila D. Caspase-8: a novel target to overcome resistance to chemotherapy in glioblastoma. Int $J$ Mol Sci. 2018;19(12):3798. doi:10.3390/ ijms 19123798
30. Zaman S, Wang R, Gandhi V. Targeting the apoptosis pathway in hematologic malignancies. Leuk Lymphoma. 2014;55(9):1980-1992. doi:10.3109/10428194.2013.855307

31. Schenk RL, Strasser A, Dewson G. BCL-2: long and winding path from discovery to therapeutic target. Biochem Biophys Res Commun. 2017;482(3):459-469. doi:10.1016/j.bbrc.2016.10.100

32. Levy JMM, Towers CG, Thorburn A. Targeting autophagy in cancer. Nat Rev Cancer. 2017;17(9):528-542. doi:10.1038/nrc.2017.53

33. Li YJ, Lei YH, Yao N, et al. Autophagy and multidrug resistance in cancer. Chin J Cancer. 2017;36(1):52. doi:10.1186/s40880-017-0219-2

34. Tanida I, Ueno T, Kominami E. LC3 conjugation system in mammalian autophagy. Int J Biochem Cell Biol. 2004;36(12):2503-2518. doi:10.1016/j.biocel.2004.05.009

35. Zhang N, Li L, Wang J, et al. Study of autophagy-related protein light chain 3 (LC3)-II expression levels in thyroid diseases. Biomed Pharmacother. 2015;69:306-310. doi:10.1016/j.biopha.2014.12.021

36. Fernandez AF, Sebti S, Wei Y, et al. Disruption of the beclin 1-BCL2 autophagy regulatory complex promotes longevity in mice. Nature. 2018;558(7708):136-140. doi:10.1038/s41586-018-0162-7

37. Tian Y, Jia SX, Shi J, et al. Polyphyllin I induces apoptosis and autophagy via modulating JNK and mTOR pathways in human acute myeloid leukemia cells. Chem Biol Interact. 2019;311:108793. doi:10.1016/j.cbi.2019.108793

38. Scherz-shouval R, Elazar Z. Regulation of autophagy by ROS: physiology and pathology. Trends Biochem Sci. 2011;36(1):30-38. doi:10.1016/j.tibs.2010.07.007

39. Teng JF, Mei QB, Zhou XG, et al. Polyphyllin VI induces caspase-1-mediated pyroptosis via the induction of ROS/ NF-kappaB/NLRP3/GSDMD signal axis in non-small cell lung cancer. Cancers (Basel). 2020;12(1):193. doi:10.3390/ cancers 12010193

40. Wu J, Zheng W, Rong L, Xing Y, Hu D. Bicyclol exerts an anti-tumor effect via ROS-mediated endoplasmic reticulum stress in human renal cell carcinoma cells. Biomed Pharmacother. 2017;91:1184-1192. doi:10.1016/j.biopha.2017.05.041

41. Du X, Fu X, Yao K, et al. Bcl-2 delays cell cycle through mitochondrial ATP and ROS. Cell Cycle. 2017;16(7):707-713. doi:10.1080/ 15384101.2017.1295182

42. Zang YQ, Feng YY, Luo YH, et al. Quinalizarin induces ROSmediated apoptosis via the MAPK, STAT3 and NFkappaB signaling pathways in human breast cancer cells. Mol Med Rep. 2019;20 (5):4576-4586. doi:10.3892/mmr.2019.10725

43. Che Y, Wang J, Yuan Z, et al. The therapeutic effects of Longikaurin A, a natural ent-kauranoid, in esophageal squamous cell carcinoma depend on ROS accumulation and JNK/p 38 MAPK activation. Toxicol Lett. 2017;280:106-115. doi:10.1016/j.toxlet.2017.08.005
OncoTargets and Therapy

\section{Publish your work in this journal}

OncoTargets and Therapy is an international, peer-reviewed, open access journal focusing on the pathological basis of all cancers, potential targets for therapy and treatment protocols employed to improve the management of cancer patients. The journal also focuses on the impact of management programs and new therapeutic agents and protocols on patient perspectives such as quality of life, adherence and satisfaction. The manuscript management system is completely online and includes a very quick and fair peer-review system, which is all easy to use. Visit http://www.dovepress.com/ testimonials.php to read real quotes from published authors. 